\title{
A Rare Cause of Acute Abdomen: Acute Idiopathic Gastric Necrosis
}

\author{
Bulent Sultanoglu* and Kenan Demırbakan \\ Department of Surgery, Turkey
}

Received: March 12, 2018; Published: May 11, 2018

*Corresponding author: Bulent Sultanoglu, Department of Surgery, Dr. Ersin Arslan Teaching and Traning Hospital, Turkey, Email: drbulentsultan@hotmail.com

\begin{abstract}
Gastric ischemia and necrosis are rare due to the rich collateral blood flow to the stomach. Herniation, anorexia nervosa and bulimia, psychogenic polyphagia, diabetes mellitus, trauma, electrolyte disturbances, gastric volvulus and spinal conditions may cause gastric ischemia. Acute gastric ischemia and necrosis is very important due to its high mortality and morbidity. Emergent surgery should be performed due to its higher complication rates and total gastrectomy is the treatment of choice.
\end{abstract}

\section{Introduction}

ischemia and necrosis are rare due to the rich collateral blood flow to the stomach. However, if a sudden increase in gastric pressure occurs, gastric ischemia and necrosis can develop due to impairment of the intramural blood flow [1]. Also, herniation, anorexia nervosa and bulimia, psychogenic polyphagia, diabetes mellitus, trauma, electrolyte disturbances, gastric volvulus and spinal conditions may cause gastric ischemia [2,3]. In this casereport, we present a case of idiopathic gastric necrosis causing acute surgical abdomen.

\section{Case Report}

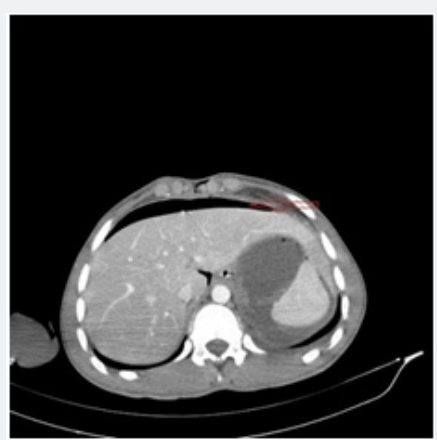

Figure 1

A18yearold malepatient, referred to our clinic from periphery hospital in Syria, after diagnostic laparatomy performed. The patient was tachypneic and tachycardic, respiratory rate of 34/ min and heart rate of $116 / \mathrm{min}$. He had a temparature of 39 ${ }^{\circ} \mathrm{C}$ and blood pressure of $90 / 60 \mathrm{~mm} \mathrm{Hg}$. His past history was not significant. The physical examination revealed abdominal distension, defense, rebound and tenderness of all abdomen quadrants. Laboratory findings were that, leukocyte count was $18930 / \mathrm{mm} 3$, hematocrit 45,5\%, hemoglobin $14.8 \mathrm{~g} / \mathrm{dl}$, platelet count was $321000 / \mathrm{L}$. Urea: $28.8 \mathrm{mg} / \mathrm{dL}$, Creatinin:075mg/dL. Abdominal computed tomography (CT) revealed free air and fluid in the abdominal cavity and intramural air bubbles within the gastric wall. (Red arrows..Figure 1-3).
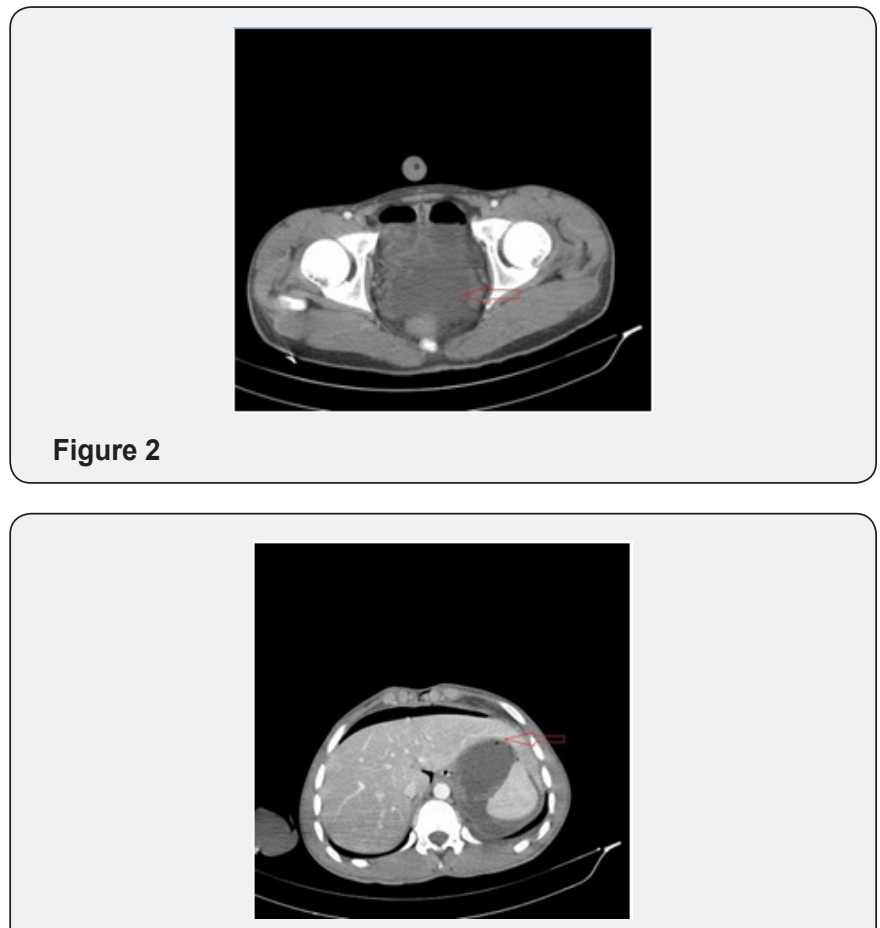

Figure 3 
The patient was taken to an emergent laparotomy with diagnosis of acute surgical abdomen. On the abdominal exploration, $1 / 3$ of proximal of the stomach was found to be completely necrotic ande perforated. (Black arrow Figure 4). There were no adhesions or volvulus. The vasculer supply was normal. The celiac trunk and superior mesenteric artery were patent. Total gastrectomy and Roux'n'Y esophagojejunostomy was performed. Distal esophagus was seen as normal. (Black arrow Figure 5). The pathological examination was interpreted as generalized transmural infarction of the gastric wall and disseminated necrosis. The patient was admitted to the intensive care unit at the postoperative period and was discharged postoperative 11 th day.

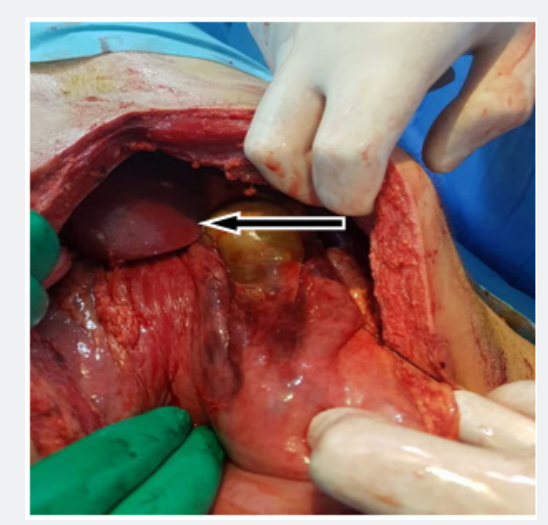

Figure 4

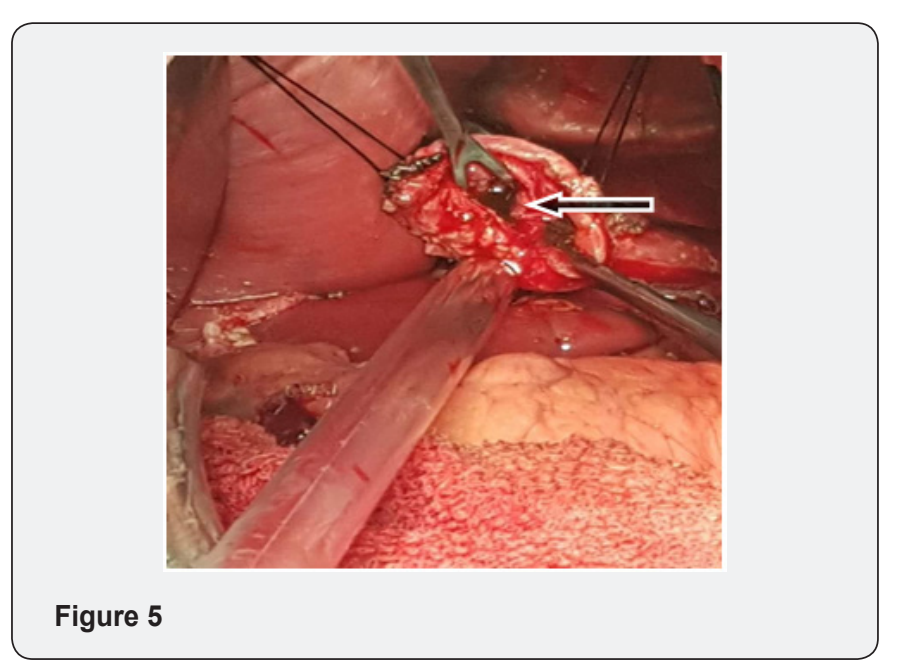

\section{Discussion}

Gastric acute ischemia and perforation have been reported first by Duplay in 1833 [4]. Acute ischemic necrosis of the stomach is very rare disease due to its abundant vasculer supply. In experimental animals, in order to produce ischemic necrosis, closure of the right and left gastric and gastroepiploic arteries together with at least $80 \%$ of the collaterals is required [5]. The important causes are postoperative complications, anorexia nervosa, bulimia, psychologic polyphagia, diabetes mellitus and vasculer problems [6]. In our case, the patient was underwent a laparotomy due to acute surgical abdomen a day before. The patient had been performed laparotomy of acute abdomen to establish the diagnosis. The presence of necrosis and perforation determines the type of surgery. If a diagnosis of gastric ischemia is being considered (with findings in direct abdominal graphy, abdomen computed tomography and physical examination), resuscitation and intravenous antibiotics should be initiated immediately. After the first treatment and resuscitation, emergent surgery should be performed. Total gastrectomy should be required if necessary. We performed total gastrectomy and Roux'en'Y esophagojejunostomy.

\section{Conclusion}

Acute gastric ischemia and necrosis is very important due to its high mortality and morbidity. Hence, the patient should be evolated correctly to avoid delay in diagnosis. Physical examination findings and radiological examinations should be evaluated carefully. Emergent surgery should be performed due to its higher complication rates and total gastrectomy is the treatment of choice.

\section{References}

1. CD Jefferiss (1972) Spontaneous rupture of the stomach in an adult. $\mathrm{Br}$ J Surg 59(1): 79-80.

2. Adson DE, Mitchell JE, Trenkner SW (1997) The superior mesenteric artery syndrome and acute gastric dilatation in eating disorders: a case report of two cases and review of the literature. Int J Eat Disord 21(2): 103-114.

3. Abdu RA, Garritano D, Culver O (1987) Acute gastric necrosis in anorexia nervosa and bulimia. Two case reports. Arch Surg 122(7): 830-832.

4. Todd SR, Marshall GT, Tyroch AH (2000) Acute gastric dilatation revisited. Am Surg 66(8): 709-710.

5. Somerwell TH (1945) Physiologic gastrectomy. Br J Surg 33: 146.

6. Byrne JJ, Cahill JM (1961) Acute gastric dilatation. The American Journal of Surgery 101(3): 301-309. 
This work is licensed under Creative Commons Attribution 4.0 License DOI:_10.19080/OAJS.2018.09.555753

\section{Your next submission with Juniper Publishers} will reach you the below assets

- Quality Editorial service

- Swift Peer Review

- Reprints availability

- E-prints Service

- Manuscript Podcast for convenient understanding

- Global attainment for your research

- Manuscript accessibility in different formats (Pdf, E-pub, Full Text, Audio)

- Unceasing customer service

Track the below URL for one-step submission https://juniperpublishers.com/online-submission.php 